COMMENT. Studies of the cognitive effects of AEDs in children are few and largely inadequate. Future studies should be controlled and of sufficient duration to evaluate the effects of AEDs on school performance and social adjustment.

\title{
NEUROLOGY OF SIGN LANGUAGE
}

The neurology of American Sign Language, which originated from French signing about 200 years ago, is reviewed by a pediatric neurologist in the UK. Sign language has its primary site of organization in the dominant hemisphere. Neuroimaging studies have shown the right cerebral hemisphere is also involved in prosodic functions and in the encoding of objects. Studies of congenital and acquired deafness and dysphasia contribute to our knowledge of cerebral localization, especially since the advent of functional MRI and PET. Broca's area of the dominant hemisphere is specialized for sign production, and the nondominant hemisphere is involved with visual-spatial functions and processing of signing, but an interplay between both hemispheres is important in the development of sign language. In childhood epileptic aphasia (Landau-Kleffner syndrome) sign language may provide an alternative means of communication, and it does not impair the acquisition of spoken speech. The importance of sign language in the deaf is shown in the book Seeing Voices (Sacks O, 1991). Cochlear implants may increase in use in the future, but sign language remains the mainstay of communication among the deaf. (Gordon N. The neurology of sign language. Brain Dev 2004;26:146-150). (Respond: Dr Neil Gordon, Huntlywood, 3 Styal Road, Wilmslow SK9 4AE, UK).

COMMENT. Sign language comprising gestures executed in space and dependent on visual spatial orientation might be thought to involve chiefly the non-dominant right cerebral hemisphere. Both hemispheres contribute to sign language but the dominant hemisphere is the primary site of organization.

\section{TOXIC AND VASCULAR DISORDERS}

\section{ACUTE MARIJUANA USE AND CEREBELLAR INFARCTION}

Three adolescent cases of ischemic stroke involving the posterior fossa circulation and cerebellum occurred within days after the illicit use of marijuana and presented over a span of 5 years at St Louis University School of Medicine, MO. Headache, fluctuating consciousness or lethargy, visual disturbance, variable dysphagia/dysarthria, and ataxia were the common presenting manifestations. Cerebellar infarction was confirmed by biopsy (1 case) or necropsy (2 cases). Cerebellar and cerebral edema without brainstem compromise or herniation led to death in the 2 fatal cases. (Geller T, Loftis L, Brink DS. Cerebellar infarction in adolescent males associated with acute marijuana use. Pediatrics April 2004;113:e365-e370). (Reprints: Thomas Geller MD, St Louis University School of Medicine, 1465 S Grand Blvd, St Louis, MO 63104). 